\title{
ANÁLISE BIBLIOMÉTRICA DAS PUBLICAÇÕES DO PROGRAMA DE CIÊNCIA, TECNOLOGIA E SOCIEDADE DA UNIVERSIDADE FEDERAL DE SÃO CARLOS
}

BIBLIOMETRIC ANALYSIS OF PUBLICATIONS FROM SCIENCE, TECHNOLOGY AND SOCIETY PROGRAM OF THE FEDERAL UNIVERSITY OF SÃO CARLOS

${ }^{1}$ Claudia Ramalho

2Jussara Oliveira

3Patrícia Martins

Universidade Federal de São Carlos 1, 2, 3

\section{Correspondência}

Claudia Ramalho

Universidade Federal de São Carlos

São Carlos, SP - Brasil

E-mail: claudinhaoliveira1985@gmail.com

iD https://orcid.org/0000-0003-1748-2942

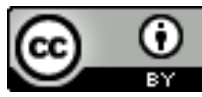

JITA: BB. Bibliometric methods

e-Location: 019024 


\title{
RESUMO
}

Este levantamento fez parte de um estudo que objetivou analisar a teoria que define o campo Ciência Tecnologia e Sociedade (CTS). A pesquisa permitiu a visualização de um panorama do desenvolvimento do próprio Programa no que diz respeito à produção científica de seus docentes e discentes colaborando para um avanço no campo científico e interdisciplinar. O levantamento acerca das publicações científicas provenientes do Programa de Pós-Graduação em Ciência, Tecnologia e Sociedade da Universidade Federal de São Carlos foi realizado tendo como base a análise bibliométrica dos principais termos presentes nos títulos e palavras-chave de publicações que incluem artigos, teses, dissertações e capítulos de livros de discentes e docentes do programa. Utilizando de tabelas, gráficos e nuvens de palavras, foram representados os principais termos apontados pelos doutorandos em uma disciplina, ingressantes da turma de 2018, bem como, pôde-se localizar a quantidade de publicações por ano, considerando o início do Programa, 2008 até 2016, e a diversidade de temas que as pesquisas se inserem, o que permitiu uma análise do perfil das pesquisas realizadas até o momento. Conclui-se que houve um aumento significativo nas publicações do Programa no que diz respeito aos artigos científicos publicados nos mais diversos periódicos. Já com relação aos capítulos de livros houve um decréscimo de publicações provavelmente pelo fato do incentivo do Programa para que os pesquisadores publiquem artigos em revistas científicas de alto impacto. O estudo também mostrou um número maior de discentes do sexo feminino do que masculino e um número equivalente de homens e mulheres entre os docentes que orientam no Programa. Os principais termos encontrados nas pesquisas são comunicação científica nas teses e dissertações, inteligência competitiva nos capítulos de livros e memória nos artigos publicados em periódicos.

\section{PALAVRAS-CHAVE}

Bibliometria. Ciência e Sociedade. Tecnologia. Publicações.

\begin{abstract}
This survey was part of a study whose purpose was to analyze the theory that defines the field Science, Technology, and Society (CTS). The survey provided an overview of the development of the Program itself, related to the scientific production of its professors and students, contributing to advances in the scientific and interdisciplinary field. The survey about the scientific publications developed in the Graduate Program in Science, Technology and Society of the Federal University of São Carlos was based on bibliometric analysis of the main terms present in the titles and keywords of publications, such as scientific papers, thesis, dissertations and book chapters of professors and students of the program. By using tables, graphs and word clouds, the main terms pointed out by the doctoral students from the 2018 class were represented, as well as the number of publications per year, since the beginning of the Program (2008 - 2016), and the diversity of themes in which the study is inserted, which allowed an analysis of the profile of the research performed so far. It was concluded that there has been a significant increase in Program's publications with respect to scientific papers published in the most diverse journals. Regarding book chapters, there has been a decrease in publications, probably due to the Program's incentive for researchers to publish papers in high-impact scientific journals. The study also showed a higher number of female than male students, and an equivalent number of men and women among advisor in the Program. The main terms found in this survey are "scientific communication", in thesis and dissertations, "competitive intelligence", in book chapters, and "memory", in papers published in journals.
\end{abstract}

\section{KEYWORDS}

Bibliology. Science and Society. Technology. Publishing. 


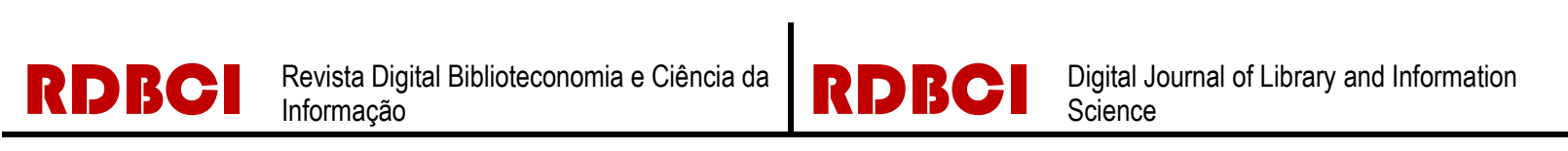
1 Introdução

A bibliometria baseia-se na contagem de artigos científicos, patentes e citações. Dependendo da finalidade do estudo bibliométrico, podem ser considerados como dados tanto o texto que compõe a publicação quanto os elementos presentes em registros sobre publicações extraídos de bases de dados bibliográficas, como nomes dos autores, título, fonte, idioma, palavras-chave, classificações e citações (RAO, 1986; ZHU et al., 1999).

Corroborando com o conceito detalhado acima, esta pesquisa apresenta um levantamento bibliométrico da produção científica dos pesquisadores do Programa de PósGraduação em Ciência, Tecnologia e Sociedade (PPGCTS) no período de 2008 a 2016. Tal produção se traduz em teses e dissertações defendidas no programa, capítulos de livros e artigos publicados em periódicos científicos.

O Programa de Pós-Graduação em Ciência, Tecnologia e Sociedade (PPGCTS) foi criado em 2007 tendo iniciado sua primeira turma de Doutorandos em 2013. O objetivo principal do PPGCTS é formar mestres e doutores em Ciência, Tecnologia e Sociedade para o desenvolvimento de pesquisas, o exercício da docência e de atividades profissional nas áreas de atuação associadas às Dimensões Sociais da Ciência e da Tecnologia, da Gestão Tecnológica e Sociedade Sustentável, e Linguagens, Comunicação e Ciência. Para compreender os impactos da ciência e da tecnologia que se estendem às esferas econômica, profissional, educativa, social e institucional da sociedade contemporânea é necessário aprofundar o conhecimento sobre as relações Ciência, Tecnologia e Sociedade (CTS), que é um objetivo interdisciplinar compartilhado por diversas disciplinas. As assimetrias sociais, educacionais e culturais também levam a uma baixa compreensão pela sociedade sobre a ciência e a tecnologia, seus aproveitamentos e impactos em sua vida. Diante disso, torna-se relevante, para a sociedade e para as organizações brasileiras, a formação de recursos humanos - profissionais, pesquisadores e docentes com maior compreensão das interrelações entre a Ciência, Tecnologia e Sociedade, de modo a contribuir para a solução dos desafios econômicos, sociais e ambientais da atualidade (PPGCTS, 2019).

O levantamento fez parte de um estudo que objetivou analisar a teoria que define o campo Ciência Tecnologia e Sociedade (CTS). A pesquisa permitiu a visualização de um panorama do desenvolvimento do próprio Programa no que diz respeito à produção científica de seus docentes e discentes colaborando para um avanço no campo científico e interdisciplinar.

Outro ponto a se analisar sobre o perfil de um campo está relacionado a análise gerada por estudos de gênero, que contribuem para investigar barreiras postas a homens e mulheres na atuação em determinados campos. Essas barreiras de segregação podem ter origem vertical ou horizontal conforme Olinto (2012). A autora ainda aponta: 


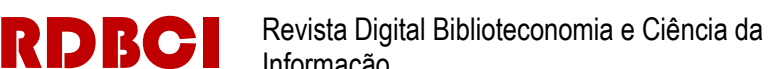

Por meio da segregação horizontal as mulheres são levadas a fazer escolhas e seguir caminhos marcadamente diferentes daqueles escolhidos ou seguidos pelos homens... A segregação horizontal inclui mecanismos que fazem com que as escolhas de carreiras sejam marcadamente segmentadas por gênero. Como as profissões femininas tendem a ser menos valorizadas no mercado de trabalho, considera-se que a segregação horizontal das mulheres está relacionada a outro tipo de segregação chamada de vertical. A segregação vertical é um mecanismo social talvez ainda mais sutil, mais invisível, que tende a fazer com que as mulheres se mantenham em posições mais subordinadas ou, em outras palavras, que não progridam nas suas escolhas profissionais (OLINTO, 2012, p. 69).

Com relação a segregação horizontal essa disparidade pode ser encontrada na separação da participação feminina entre as diferentes disciplinas, conforme enfatizam Schiebinger (2001) e Yannoulas (2007):

Hoje, as mulheres estão concentradas nas que são conhecidas como ciências soft: as ciências da vida e do comportamento e as ciências sociais, em que os salários são relativamente baixos, independente de sexo. Poucas mulheres são encontradas nas ciências hard ou físicas, cujo prestígio e pagamento são altos. (SCHIEBINGER, 2001, p. 78)

Observa-se a tendência de agrupamento das alunas universitárias em disciplinas vinculadas aos serviços, como são as profissões das áreas de Comunicação, Educação, Humanidades e Saúde. As carreiras mais fortemente vinculadas à produção, como as Ciências Agropecuárias e as Engenharias, permanecem com o corpo discente fundamentalmente masculino. (YANNOULAS, 2007, p. 4)

No PPGCTS as formações iniciais dos pesquisadores e pesquisadoras são diversas e caberia um estudo mais amplo acerca da formação das mesmas ao integrar um Programa de Pós-Graduação interdisciplinar onde as pesquisas também são das mais diversas. Entre as mulheres entrantes em 2018 no referido Programa há bibliotecárias, jornalista, analista de TI, nutricionista, bióloga, turismóloga, entre outras. O próprio caráter interdisciplinar do Programa atrai pesquisadoras com as mais distintas formações.

\section{Método}

Um dos desafios mais importantes para a ciência brasileira no século 21 é o de buscar maior impacto mundial para o conhecimento originado no país. A produção científica de qualidade requer a colaboração entre os cientistas mais capacitados (CRUZ, 2011), e pode ser mensurada pelo uso de instrumentos. Uma dessas ferramentas é a Bibliometria, que permite observar o estado da ciência e tecnologia através de toda a produção científica, atribuindo um nível de especialização. Isto significa que permite situar o país em relação ao mundo, uma instituição em relação ao país, e um cientista individual em relação a sua comunidade científica (OKUBO, 1997).

A bibliometria surge como uma forma de acompanhar o desenvolvimento da ciência, ou ao menos, de uma área do conhecimento frente a percepção dos cientistas quando a quantidade de conhecimento científico gerado ultrapassava a capacidade de leitura 


\section{RDBCI -

(ROSTAING, 1996). Esta ferramenta envolve várias medições da literatura, de documentos e outros meios de documentação enquanto a cientometria envolve a produtividade e utilidade científica fazendo uma avaliação da produção científica mediante indicadores numéricos de publicações, patentes, entre outros (SPINAK, 1998).

A partir de um conjunto de termos relacionados às principais temáticas de pesquisas desenvolvidas por doutorandos do Programa entrantes em 2018 e termos elencados de acordo com temas abordados no campo CTS, além de termos variantes relativos à teoria ou grafia no plural, foi realizado um cruzamento no intuito de identificar quais e quantos destes termos eram citados nas palavras-chave das teses e dissertações, capítulos de livros e artigos publicados em periódicos científicos. Localizando, dessa forma, os novos trabalhos dentro do histórico presente nas publicações do programa.

Os termos levantados e utilizados nas buscas estão listados na Tabela 1 abaixo:

Tabela 1. Relação dos termos utilizados para fazer o estudo bibliométrico

\begin{tabular}{|c|c|c|}
\hline Termos-1 & Termos-2 & Termos-3 \\
\hline \multicolumn{3}{|l|}{ Economia evolucionista } \\
\hline Economia da tecnologia & Institucionalismo & Neo-institucionalismo \\
\hline Construtivismo social & Abordagem normativa & \\
\hline \multicolumn{3}{|l|}{ Sociologia do conhecimento } \\
\hline Teoria ator-rede & Teoria do campo científico & \\
\hline Modelo tríplice-hélice & $\begin{array}{l}\text { Novo modo de produção } \\
\text { do conhecimento }\end{array}$ & \\
\hline Comunicação Pública da Ciência & $\begin{array}{l}\text { Compreensão Pública da } \\
\text { Ciência }\end{array}$ & Comunicação Científica \\
\hline Sociologia ambiental & $\begin{array}{l}\text { Teoria da modernização } \\
\text { ecológica }\end{array}$ & \\
\hline Modernidade reflexiva & Sociedade de risco & \\
\hline \multicolumn{3}{|l|}{ Teoria de gênero } \\
\hline Pós-modernismo & Pós-colonialismo & \\
\hline Teoria das representações sociais & Representação social & \\
\hline \multicolumn{3}{|l|}{ Identidade } \\
\hline Tecnologia social & Tecnologias sociais & \\
\hline Política pública & Política pública CTS & Políticas públicas \\
\hline \multicolumn{3}{|l|}{ Inteligência Competitiva } \\
\hline \multicolumn{3}{|l|}{ Inteligência Coletiva } \\
\hline \multicolumn{3}{|l|}{ Etnografia } \\
\hline Memória & & \\
\hline
\end{tabular}

Fonte: resultados da pesquisa.

\begin{tabular}{l|l|l|l} 
v.17 & $1-16$ & $\mathrm{e} 019024$
\end{tabular}




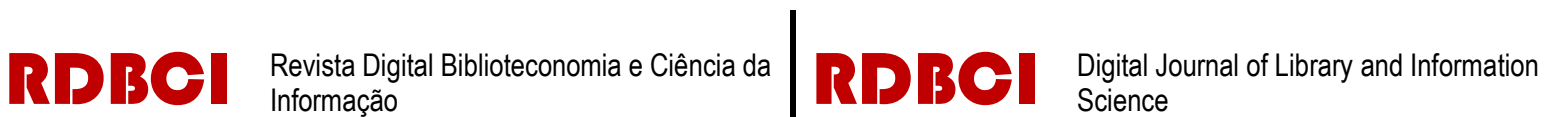

A partir desses termos elencados acima foram realizadas buscas os considerando nos títulos e palavras-chave de publicações de artigos em periódicos científicos, capítulos de livros e teses e dissertações defendidas no PPGCTS.

A primeira etapa do levantamento consistiu em analisar as teses e dissertações defendidas no Programa depositadas no repositório institucional da UFSCar. O website do repositório permite que a busca seja realizada usando como filtro o programa de pósgraduação, assunto, autor, orientador, título, data, tipo de documento e áreas do CNPq. Através de uma solicitação ao setor responsável pela inserção das teses e dissertações no repositório atrelado à Biblioteca Comunitária da UFSCar (BCo) e também à Secretaria Geral de Informática (SIn) foi possível ter acesso a um relatório no qual incluiu-se também as palavras-chave dos trabalhos.

O Repositório Institucional da UFSCar (RI UFSCar) é um sistema de informação que visa armazenar, preservar, organizar e disseminar amplamente a produção intelectual dos diversos setores e segmentos da comunidade da UFSCar, provendo o acesso aberto à informação produzida na instituição e registrada como científica, tecnológica, didática, artístico-cultural e técnico-administrativa (RI UFSCAR, 2018).

Na segunda etapa do levantamento foram selecionados os capítulos de livros publicados no programa considerando os títulos das obras no todo, dos capítulos e dos respectivos autores. Neste caso, devido às publicações não conterem palavras-chave o cruzamento dos termos foi retirado dos títulos.

Por conseguinte, foi realizado a busca dos artigos publicados em periódicos científicos entre os anos de 2013 a 2016, a partir de uma lista destas publicações disponíveis no site do próprio programa com informações acerca dos autores, título do artigo, título do periódico, volume, número e ano. Com base nessas informações foi feita a busca por artigo ora via portal da Capes, ora pelos websites das revistas, recuperando assim, na maior parte das vezes, as palavras-chave das publicações. Para inserção e tabulação dos dados foi usado um aplicativo de edição de planilha eletrônica, a fim de contabilizá-los, gerar os resultados finais e os gráficos que serão apresentados a seguir.

\section{Resultados}

A fim de iniciar a apresentação dos resultados, segue o gráfico 1 abaixo que compila o número de publicações das modalidades citadas por ano (de 2008 a 2016) do referido Programa. Os resultados apresentam o volume total das publicações do Programa por tipo de publicação, as quais são: artigos, capítulos de livros, teses e dissertações. 


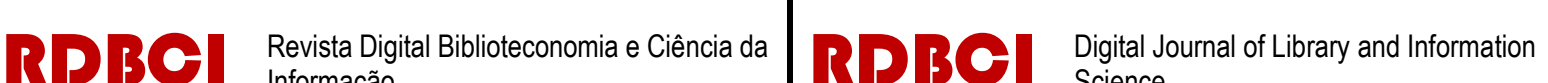

Gráfico 1. Volume de publicações entre artigos, capítulos de livros, teses e dissertações

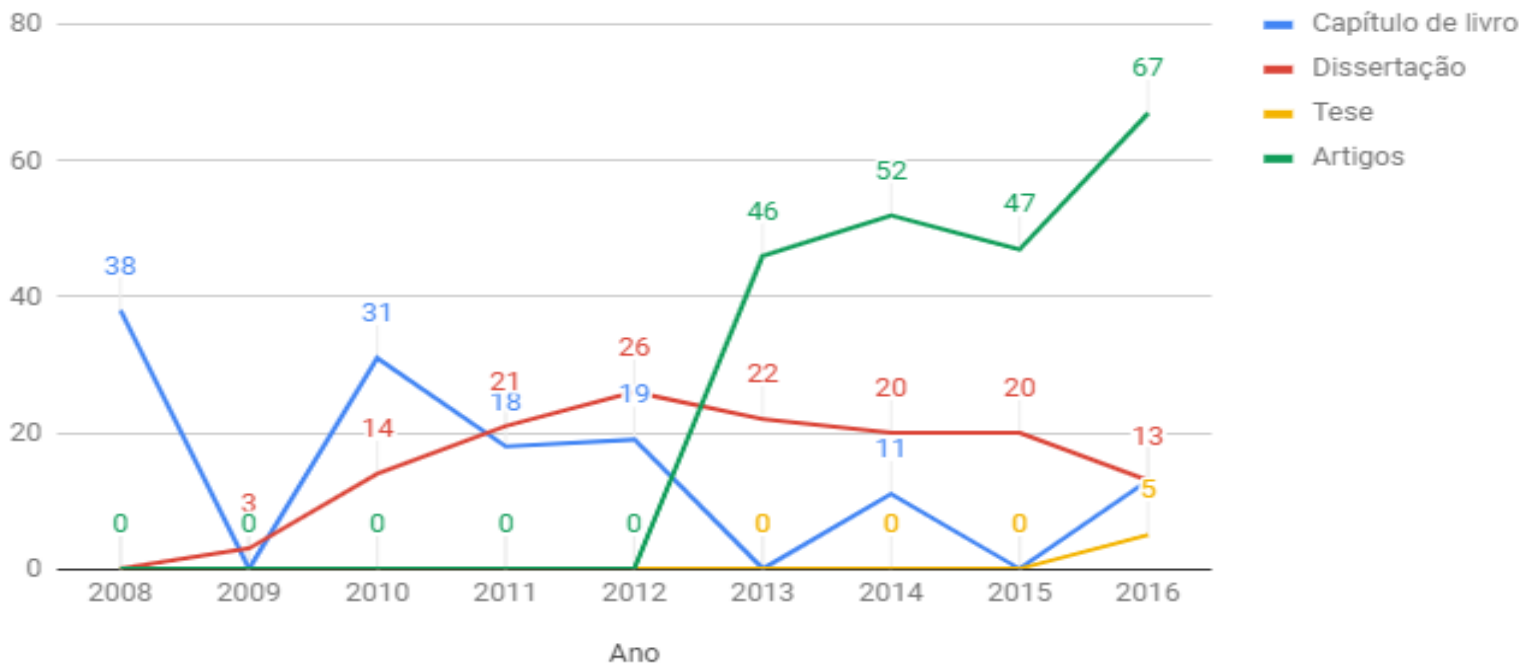

Fonte: resultados da pesquisa.

É possível observar um crescimento nas publicações de artigos em periódicos a partir de 2012 enquanto o volume de publicações de capítulos de livros diminuiu. Possivelmente, isto ocorre devido às mudanças atreladas às exigências da Capes com relação a avaliação quadrienal feita dos programas de pós-graduação onde as publicações de artigos em periódicos científicos bem avaliados no qualis Capes elevam as notas dos programas. $\mathrm{O}$ ano de 2017 não foi considerado, pois diversas publicações encontram-se no prelo ou ainda não foram computadas junto ao PPGCTS.

Conforme Kawasaki (2017, p. 110) “a publicação qualificada de artigos de periódicos quanto a de capítulos e livros encontram-se em ascensão e possuem significativo efeito de discriminação sobre o desempenho dos Programas". A publicação em anais de eventos, capítulos e livros têm baixo peso em relação a artigos em periódicos e patentes.

Houve também um crescimento na quantidade de teses e dissertações defendidas no Programa refletindo o crescimento do próprio Programa ao longo do tempo. A primeira turma de doutorandos iniciou os estudos em 2013 e as primeiras defesas de tese ocorreram já em 2016, bem como as defesas de dissertações, sendo a primeira defendida em 2009.

Além dos gráficos foram também utilizadas nuvens de palavras. De acordo com Silva (2013) nuvens de palavras são vários termos utilizados para certo tipo de visualização onde cada palavra tem seu tamanho orientado pela relevância em determinado corpus de texto. Normalmente se trata de contagem simples das ocorrências de determinada palavra no texto. A ferramenta se mostrou útil para demonstrar de forma visual a concentração de alguns termos quando as possibilidades são muito variadas, como na autoria dos trabalhos e palavras chaves utilizadas. 
RDBCI

A seguir apresentam-se as ilustrações com nuvens de palavras criadas a partir dos títulos e palavras-chave das publicações dos capítulos de livros, artigos e dissertação e tese. No caso de capítulos de livros, conforme já citado não havia palavras-chave disponíveis, portanto, foram utilizadas buscas nos títulos somente. Já para as demais publicações, artigos e dissertações e teses, foram utilizados os termos contidos na Tabela 1.

Figura 1. Nuvem de palavras encontradas nos títulos de capítulo

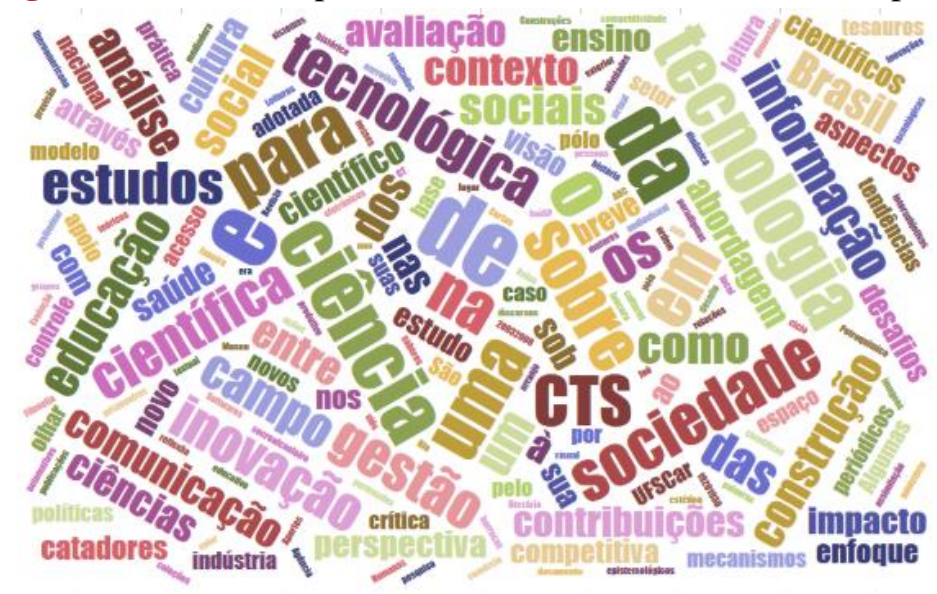

Fonte: resultados da pesquisa.

Nas nuvens de palavras apresentadas na Figura 1 acima na modalidade de capítulo de livro, é possível identificar os termos que aparecem com grande frequência como ciência, tecnologia, sociedade, tecnológica, científica, inovação, educação, comunicação, CTS entre outros.

Figura 2. Nuvem de palavras encontradas nos títulos e nas palavras-chave das publicações.

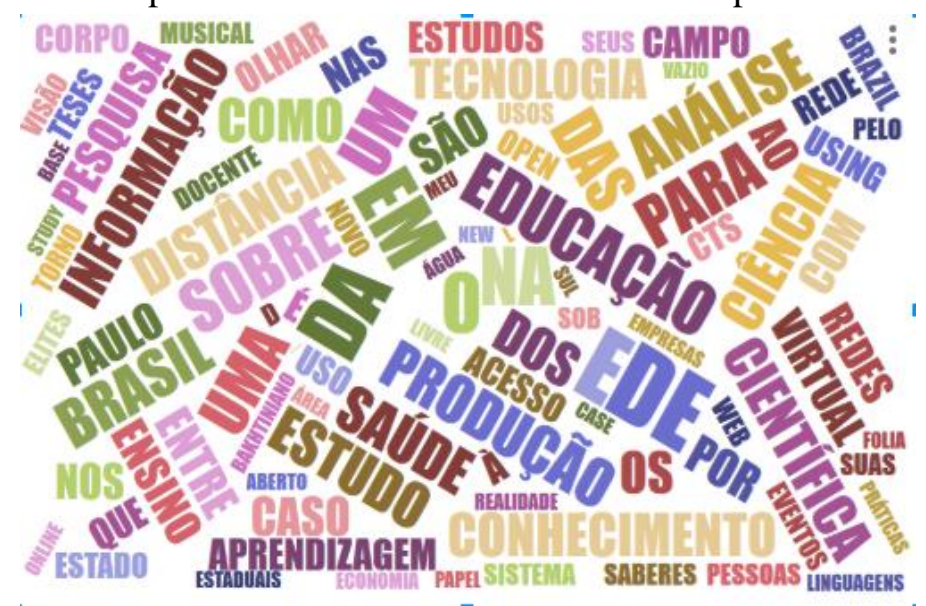

Fonte: resultados da pesquisa.

Já na Figura 2 na modalidade de artigos, temos também a incidência de ciência, educação, CTS, informação, como também novos termos: saúde, produção, conhecimento, tecnologia, linguagem, redes virtuais, entre outros. 
Figura 3. Nuvem de palavras encontradas nos títulos e nas palavras-chave atribuídas pelos autores nas publicações de dissertações e teses

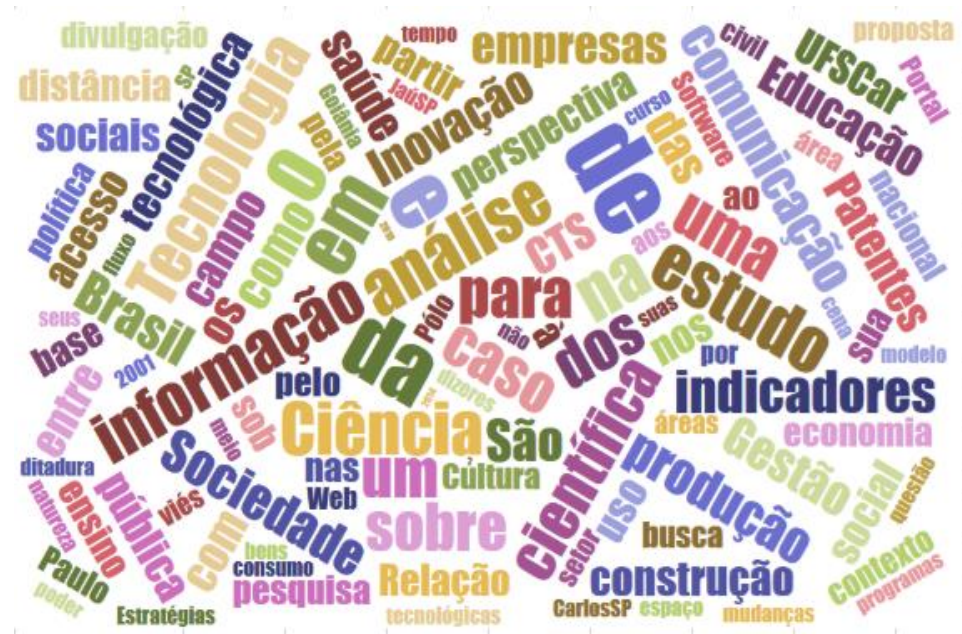

Fonte: resultados da pesquisa.

Na Figura 3 em dissertações e teses, algumas palavras se repetem, como também há novos termos como: indicadores, economia, patentes, software, empresas, entre outros.

Observa-se que as palavras repetidas nas 3 nuvens são: ciência, científica, educação, CTS, informação. As palavras em destaque mostram a variedade de temas pesquisados no PPGCTS, porém, destaca o foco em alguns campos.

Dentre os termos localizados nas teses e dissertações os mais expressivos foram comunicação científica, inteligência competitiva, políticas públicas e tecnologia social seguidos de comunicação pública da ciência, gênero e memória conforme mostra o Gráfico 2 a seguir.

Gráfico 2. Principais termos encontrados nas teses e dissertações

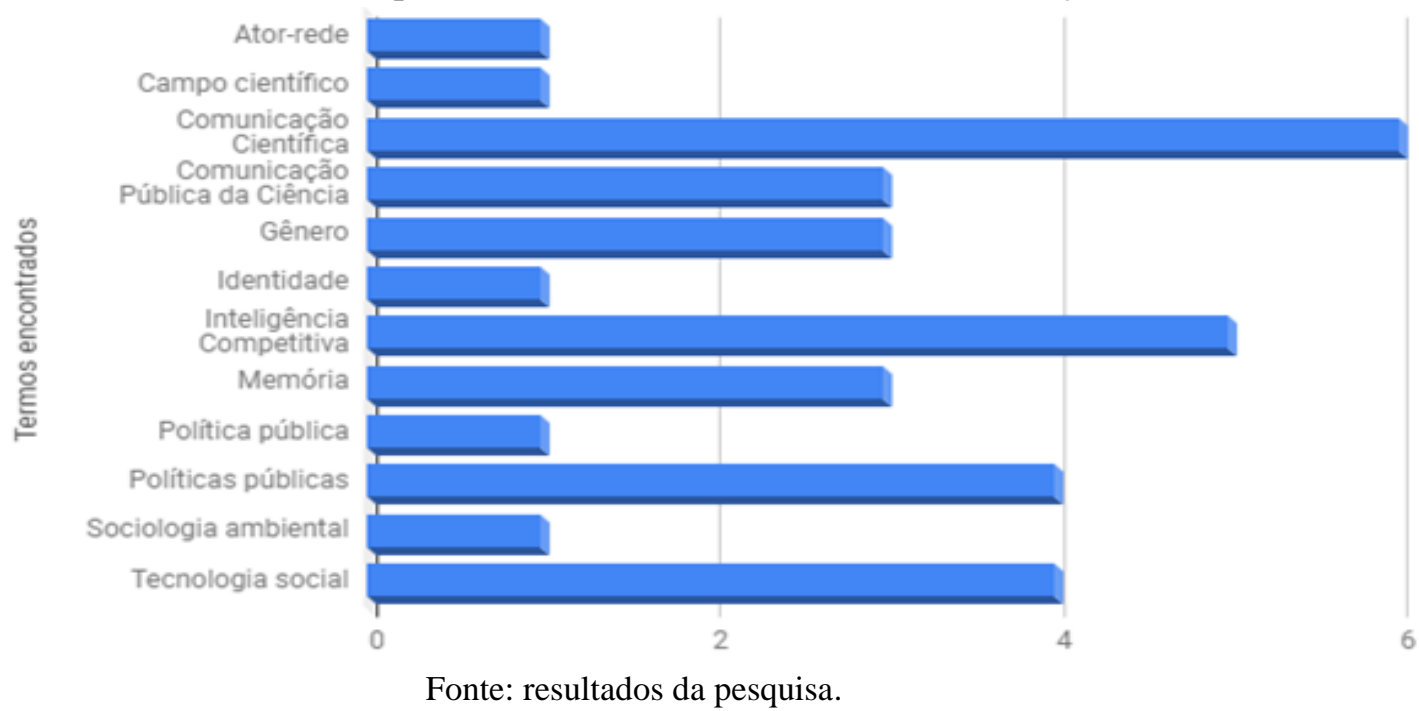


Com relação aos capítulos de livros os termos que aparecem com maior frequência também foram inteligência competitiva e comunicação pública da ciência juntamente com tecnologia social conforme observamos no Gráfico 3 a seguir:

Gráfico 3. Número de termos encontrados em capítulos de livros

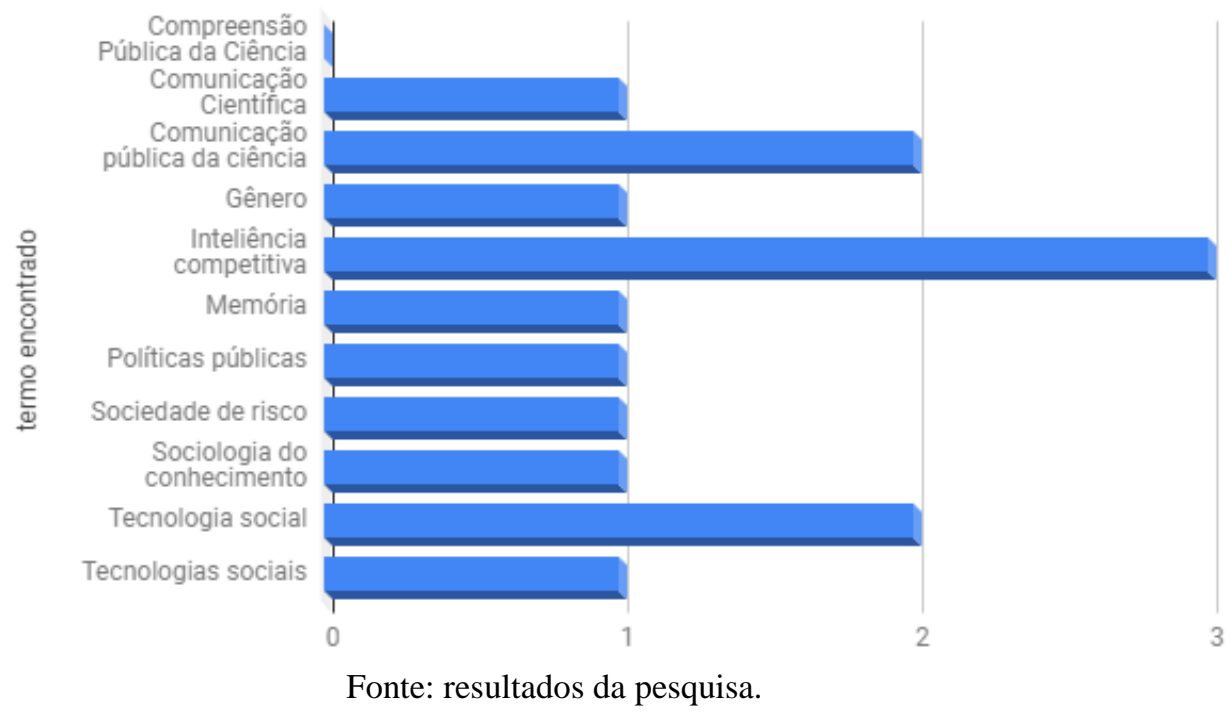

Nas publicações de artigos em periódicos científicos os termos memória e produção do conhecimento tem maior expressividade seguidos dos termos gênero, sociedade de risco e tecnologias sociais, conforme Gráfico 4 a seguir:

Gráfico 4. Número de termos encontrados em artigos.

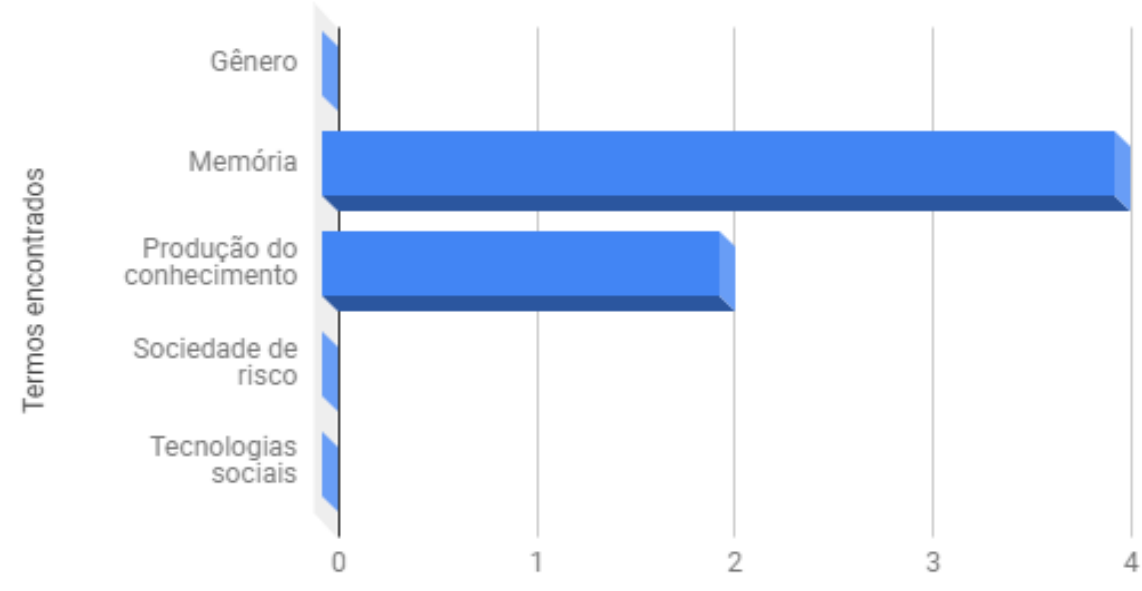

Fonte: resultados da pesquisa. 


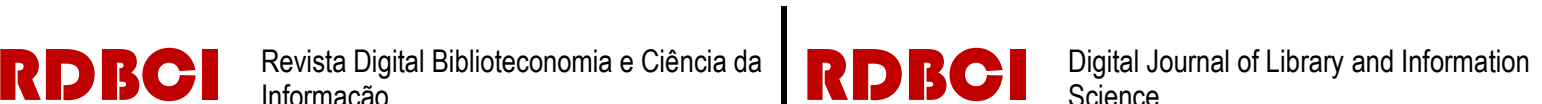

Foi observado que a classificação das palavras-chaves nos artigos não foi tão exata, pois difere bastante do que foi encontrado em artigos, dissertações e teses. Dos termos encontrados, dá para constatar que nas publicações de livros, dissertações e teses, há uma repetição das palavras: comunicação científica, comunicação pública da ciência, inteligência competitiva e tecnologia social. A palavra-chave em comum encontrada nas publicações de artigos e livros foi memória. Comparando as publicações de artigos com dissertações e teses não foi observado nenhuma repetição.

Abaixo segue uma ilustração com os termos encontrados em todos os tipos de publicação sendo que o algarismo que aparece na frente do termo corresponde ao número de vezes em que o termo aparece. Para os termos onde não aparece nenhum algarismo significa que o termo não foi encontrado:

Tabela 2. Relação dos termos encontrados nas publicações do Programa de Pós-Graduação em Ciência, Tecnologia e Sociedade da UFSCar

\begin{tabular}{|c|c|c|}
\hline Teses e dissertações & Capitulos de livros & Artigos em periódicos \\
\hline Ator-rede (1) & Compreensão Pública da Ciência & Gênero \\
\hline Campo científico (1) & Comunicação Científica (1) & Memória (4) \\
\hline Comunicação Científica (6) & $\begin{array}{l}\text { Comunicação pública da ciência } \\
\text { (2) }\end{array}$ & Produção do conhecimento (2) \\
\hline $\begin{array}{l}\text { Comunicação Pública da Ciênci } \\
\text { (3) }\end{array}$ & Gênero (1) & Sociedade de risco \\
\hline Gênero (3) & Inteliência competitiva (3) & Tecnologias sociais \\
\hline Identidade (2) & Memória (1) & \\
\hline Inteligência Competitiva (5) & Políticas públicas (1) & \\
\hline Memória (3) & Sociedade de risco (1) & \\
\hline Política pública (1) & Sociologia do conhecimento (1) & \\
\hline Políticas públicas (4) & Tecnologia social (2) & \\
\hline Sociologia ambiental (1) & Tecnologias sociais (1) & \\
\hline
\end{tabular}

Fonte: resultados da pesquisa.

\begin{tabular}{l|l|l|} 
v.17 & $1-16$ & $\mathrm{e} 019024$ \\
\hline
\end{tabular}


Com relação a investigação sobre gênero nas publicações de teses e dissertações encontramos os seguintes resultados:

Gráfico 5. Proporção entre os discentes por gênero no PPGCTS.

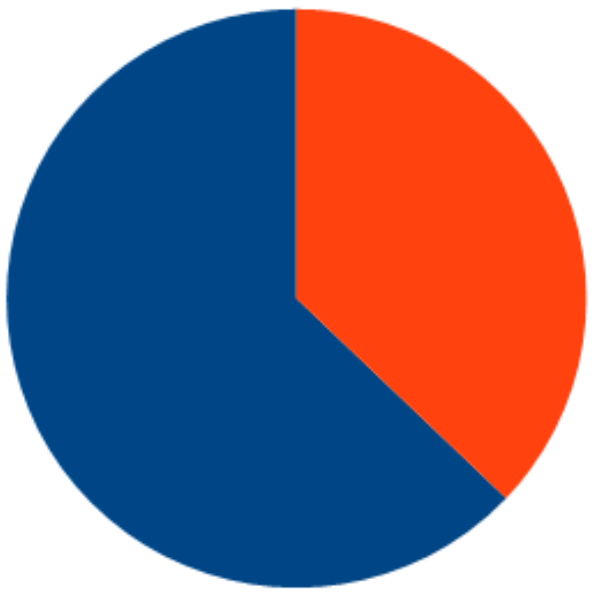

Fonte: resultados da pesquisa.

Dentre as publicações do programa pode-se observar que há uma maioria feminina entre as discentes. Levando em conta que o curso tem uma predominância de disciplinas da área de humanas/sociais essa diferença reitera a segregação horizontal de gênero demonstrando uma predominância feminina na área, que não se mantém entre os discentes, ao menos nas publicações de teses e dissertações. Indicando uma possibilidade de segregação vertical onde parece mais difícil para que mulheres se tornem discentes/orientadoras no curso de maioria feminina. Conforme apontam Schiebinger (2001), Yannoulas (2007) e Olinto (2012).

Gráfico 6. Proporção entre orientador/orientando por gênero no PPGCTS.

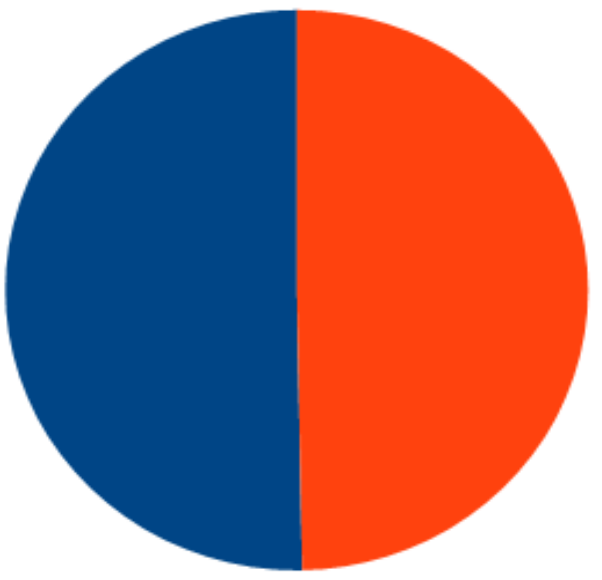

Dados

- Orientador

- Orientadora

Fonte: resultados da pesquisa. 


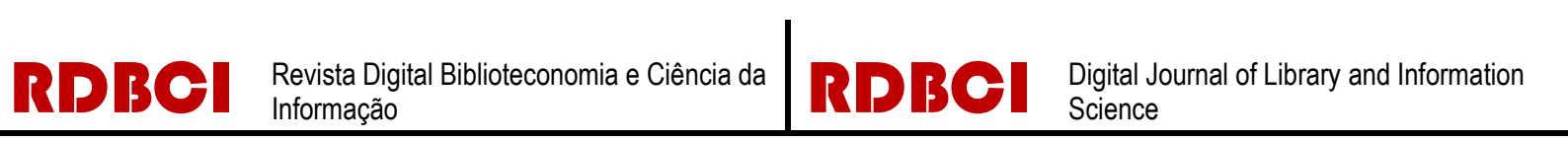

No gráfico acima observamos que dentre as publicações do programa o número de orientadores e orientadoras é praticamente o mesmo. O que traz o questionamento sobre a disparidade de gênero vertical de que se há maioria entre as discentes porque razão não observamos a mesma diferença entre os orientadores.

\section{Considerações finais}

O objetivo deste estudo referente ao levantamento bibliométrico para análise das principais temáticas que definem o campo Ciência, Tecnologia e Sociedade (CTS) acerca das publicações científicas provenientes do Programa de Pós-Graduação em Ciência, Tecnologia e Sociedade, foi atendido, e, consequentemente, alguns resultados puderam ser observados e serão explicitados a seguir.

Uma diversidade de termos relacionados de diferentes teorias e temas de estudo foi observada tanto na publicação de artigos e capítulos de livros quanto nas dissertações e teses. Esta diversidade pode estar relacionada ao fato do Programa ter um caráter interdisciplinar abrangendo estudos nas mais diversas áreas do conhecimento.

Conforme Okubo (1997) preconiza foi possível, através da bibliometria, situar as principais temáticas utilizadas pelos doutorandos da turma de 2018 com relação aos trabalhos publicados do programa por meio da busca de palavras-chave. Além de iniciar uma identificação de alguns padrões e relevância de assuntos nas publicações através das nuvens de palavras, conforme proposto por Silva (2013).

O termo que mais apareceu nas teses e dissertações foi comunicação científica. Tal dado pode estar relacionado ao fato de que nos últimos anos, e principalmente no momento político atual, a academia como um todo venha discutindo mais amplamente a importância da comunicação científica não somente entre os pares, mas principalmente com a sociedade a fim de reafirmar a importância do desenvolvimento científico e até mesmo do financiamento para as pesquisas.

Entre os artigos publicados em periódicos científicos o termo que mais apareceu foi memória. Camargo e Goulart (2015) apontam que a partir dos anos 1980 começaram a surgir no Brasil os centros de memória ligados a organizações públicas e privadas e embora não se tenha dados mais exatos sobre isto, é possível traçar um paralelo do crescimento numérico desses centros de memória a elementos de conjuntura que trazem à tona a necessidade de preservação da cultura e identidade das organizações. O termo memória por si só é bastante amplo de sentido de maneira que as publicações podem estar relacionadas a memória institucional, memória cultural, memória científica, entre outros. 


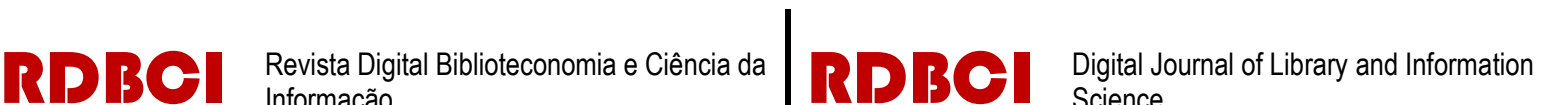

Com relação aos capítulos de livros o termo que mais se destacou foi inteligência competitiva, entretanto, este tipo de publicação no Programa teve um decréscimo em número de publicações enquanto os artigos e teses e dissertações tiveram um aumento que no caso deste último está atrelado ao próprio crescimento do programa em número de alunos.

Mesmo com uma maioria feminina entre as discentes do Programa, pode-se observar uma maioria feminina entre as discentes e uma divisão igualitária nas orientações gerando um indício (que precisa ser melhor investigado) de segregação de gênero horizontal, pela segregação de áreas e vertical por esta não se manter numa posição de maior destaque, que é a de docente/orientação. Podemos sugerir como estudos futuros uma análise de gênero (inclusive com mais recortes como raça, por exemplo) mais ampla que englobe análise de produtividade, reconhecimento, e segregação no programa PPGCTS e em outros programas interdisciplinares para traçar um perfil com suas limitações neste campo. Dessa forma seria também interessante a análise de gênero para as publicações de livros e artigos, que poderiam complementar essa análise.

Através deste estudo foi possível observar a importância da escolha do título e das palavras-chave de uma publicação, pois foram através delas que o trabalho foi guiado. Nesse sentido, os pesquisadores têm um papel muito importante na divulgação científica ao influenciar a recuperação de resultados encontrados em buscas de bases de dados por outros pesquisadores em momentos futuros. A escolha das palavras-chave é crucial na recuperação dos trabalhos acadêmicos indexados nas bases de dados e identifica por qual tema um trabalho será reconhecido ao ser recuperado. A partir das palavras-chave encontradas é possível inferir que o PPGCTS cumpre com sua proposta abrangente e multidisciplinar, pois há pesquisas abordando os mais diversos temas como: memória, inteligência competitiva, ciência, educação, gênero, tecnologias sociais, saúde, entre outros. O campo CTS aparece ainda timidamente.

Para trabalhos futuros pode-se considerar uma análise comparativa com os produtos gerados por outros programas de pós-graduação com propostas similares, além de agregar outros fatores como a observação dos termos utilizados em resumos, concentração de publicações com determinadas temáticas, relação de autoria e coautoria, entre outros. 


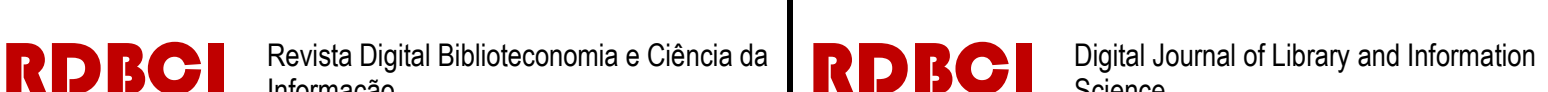

\section{Referências}

CAMARGO, A. M.; GOULART, S. Centros de memória: uma proposta de definição. São Paulo: Edições SESC São Paulo, 2015.

CRUZ, C. H. B. Desafios e estratégias para a cooperação internacional em pesquisa no Brasil e as FAPs. Revista Eletrônica de Jornalismo Científico, Campinas, jun. 2011. Disponível em: http://www.comciencia.br/comciencia/?section=8\&edicao=67\&id $=852$. Acesso em: 10 set. 2018.

KAWASAKI, B. C. Critérios da avaliação Capes para programas de pós-graduação. Revista Adusp, São Paulo, v. 60, p. 102 - 117, 01 maio 2017.

OKUBO, Y. Bibliometric indicators and analysis of research systems: methods and examples. Paris: OECD, 1997. Disponível em: http://www.oecd-ilibrary.org/ docserver/download/fulltext/5lgsjhvj7ng0.pdf?expires=1308322145\&id=id\&accname=guest \&checksum=BAFB93375234F0FCD0CBA6DA4E2BC1DA. Acesso em: 24 ago. 2018.

OLINTO, G. A inclusão das mulheres nas carreiras de ciência e tecnologia no Brasil. Inclusão Social, Brasília, v. 5, n. 1, p. 68-77, 2012. Disponível em: revista.ibict.br/inclusao/article/view/1667. Acesso em: 25 de fev. 2019.

PPGCTS. Histórico. Disponível em: http://www.ppgcts.ufscar.br/apresentacao. Acesso em: 18 ago. 2019.

RAO, I. K. Métodos quantitativos em biblioteconomia e ciência da informação. Brasília: ABDF, 1986.

RI UFSCAR. Sobre o repositório. Disponível em: https://repositorio.ufscar.br/. Acesso em: 10 set. 2018.

ROSTAING, H. La bibliométrie et ses techniques. Collection "Outils et méthodes", coédition sciences de la societé et CRRM - Centre de Recherche Rétrospective de Marseille. Marseille. 1996.

SCHIEBINGER, L. O feminismo mudou a ciência?. Tradução Raul Fiker. Bauru: EDUSC, 2001. 384 p.

SILVA, T. O que se esconde por trás de uma nuvem de palavras? 2013. In: Blog Tarcízio Silva. Disponível em: http://tarciziosilva.com.br/blog/o-que-se-esconde-por-tras-de-umanuvem-de-palavras/. Acesso em: 09 set. 2017.

SPINAK, E. Indicadores cienciométricos. Ciência da Informação, Brasília, DF, v. 27, n. 2 , p. 141-148, 1998.

YANNOULAS, S. Mulheres e Ciência. Scielo, SérieAnis, n. 47, p. 1-10, 2007. 
ZHU, D. et al. A process for mining science \& technology documents databases illustred for the case of knowledge discovery and data mining. Ciência da Informação, Brasília, DF, v. 28, n.1, jan. 1999. Disponível em:

http://www.scielo.br/scielo.php?script=sci_arttext\&pid=S0100-19651999000100002. Acesso em: 08 jun. 2018.

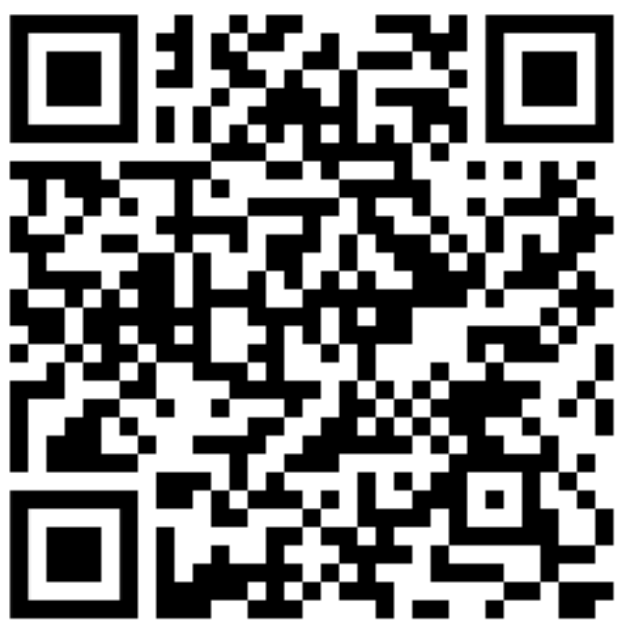

